\section{Parametric process of a box-counting model for evaluation of fractal compositions}

Processo paramétrico de um modelo de box-counting para avaliação de composições fractais

\section{Pedro Oscar Pizzetti Mariano *, Gabriela Pinho Mallmann**}

*Pedro Oscar Pizzetti Mariano: Possui graduação em Arquitetura e Urbanismo pela Universidade do Estado de Santa Catarina - UDESC (2014). Pós-graduação em Arquitetura, Construção e Gestão de Edificações Sustentáveis, pela AVM Faculdade Integrada (2016). Mestre pelo programa Pós-Arq UFSC. E atualmente é doutorando pelo Pós-Arq UFSC, pedro.pm@hotmail.com

**Gabriela Pinho Mallmann: Graduanda em Arquitetura e Urbanismo na Universidade Federal de Santa Catarina (UFSC). Foi bolsista do grupo PET (Programa de Educação Tutorial) do Departamento de Arquitetura e Urbanismo da UFSC, gabrielapinhomallmann@gmail.com

\section{Palavras-chave:}

Processo paramétrico.

Box-counting;

Fractal.

\section{Keywords:}

Parametric process.

Box-counting;

Fractal.

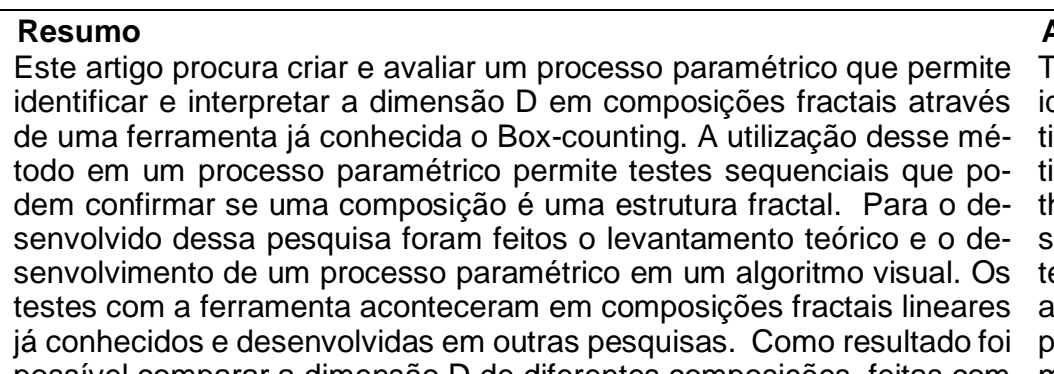
padrões geométricos fractal. E como conclusão foi possível observar que o processo do método Box-counting através de uma ferramenta paramétrica foi bem-sucedido ao possibilitar avaliar composições e arranjos de modo ágil. Também se identificou uma relação direta entre as ite- usjt

\section{arq.urb} Recebido: 31/03/2021 número 31 | maio - ago de 202 Aceito: $30 / 06 / 2021$ raçôes usadas nos padrões e o aumento proporcional da dimensão D.

\section{Abstract}

This article seeks to create and evaluate a parametric process that allows dentifying the $\mathrm{D}$ dimension in fractal compositions through a Box-couning tool. The use of this method in a parametric process allows sequential tests that can confirm whether a composition is a fractal structure. The theoretical survey and the development of a parametric process in a visual algorithm were carried out for the development of this research. The tests with the tool took place in linear fractal compositions already known and developed in another research. As a result, it was possible to compare the $D$ dimension of different compositions, made with fractal geometric patterns. In the conclusion, it was possible to observe that the process through a parametric tool was successful in making it possible to evaluate compositions and arrangements in an agile way. A dirst relationship was identified and arrangements in an agile way. A direct relati-

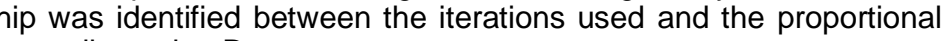
increase dimension $\mathrm{D}$. 


\section{Introdução}

This article is part of a master's thesis that sought to evaluate the interpretation of daylight behavior resulting from the use of facade elements with geometric characteristics based on the rules of linear fractals. The part described and expanded in this article presents the development and evaluation of a parametric process, combined with a well-known Box-counting method, which allows identifying whether a composition has characteristics of fractal geometry, the $D$ dimension. The use of this method in a parametric process can enhance its use, enabling its use in a sequential and agile way (MARIANO, 2018).

What arouse the development of this process of evaluating the fractal dimension in the facade elements, in addition to the present appearance of this type of geometry in different architectural projects throughout history, is the possible positive relationship that fractal characteristics can bring to the human psychological. This positive psychological reading of space comes through a fractal characteristic described by Mandelbrot (1977) as the " $\mathrm{D}$ " dimension. The use of this geometry as a tension reduction device can be found in studies such as Wise and Rosenberg (1986) and Hargerhall, Purcell and Taylor (2004), Salingaros (2003) and (2012), Taylor (2006) and Joye (2007).

The use of fractal geometry in façade elements for the control and distribution of natural light, can be justified based on the fact of those patterns has been interpreted and applied in buildings since the beginning of the settlements. The application of any standards to guide human compositions is a common instrumentation within architecture, being present in human compositions for centuries, found in the formation of floor plans, facades and ornaments (SALINGAROS 2012, ROOM 2003).

This article was divided into two main parts, the theoretical basis and the formation and application of a parametric process in a visual algorithm. In the first part, the theoretical basis for the interpretation of fractal geometry, its use in architecture and the Box-Counting method is described. Next, the tools and the development of the parametric process are presented, which is able to identify whether the geometry used and its composition can be considered as a fractal pattern. To obtain the result, the process went through a sequence of actions for its validation, using facade elements already developed. At the end, the results were compared quantitatively, ma- king it possible to conclude the validation of the parametric process with the method, and an association between the $\mathrm{D}$ dimension and the iteration of the fractals used.

\section{Theoretical Framework}

Different geometric patterns are applied and observed since the first human constructions. Like the use of Euclidean proportions and geometries that has been used through mathematical patterns in buildings, ornaments, arts, mosaics, paintings and sculptures, for example (WAIHRICH et al., 2010). Designs, components and ornaments, referenced in elements of nature, are clearly present throughout human history. The reproduction of natural forms can be observed in different places and historical periods. The appropriation of natural elements in architectural elements is evidenced by the human interest in following certain standards in the field of architecture and urbanism. These different patterns allow for their identification, historical interpretation and the reproduction of their sensations (RUMIEZ, 2013).

Within the different existing patterns, the chaotic group, defined by the thought that a part can influence the behavior of an entire structure and its organization, is an ideology applied to architecture since the first constructions. This connection that combines patterns, natural forms and geometry is used by artists, architects and designers in the development of fundamental concepts and works. The application of nature-inspired patterns applied to architecture seeks to improve the human capacity to understand the formal balance of different compositions and diversity as a whole. Euclidean geometric patterns, when they tend to reproduce the forms of nature, can be inadequate or incomplete, because many forms found in nature do not belong to the group of Euclidean geometries (LANGHEIN, 2005; HARRIS, 2007).

In many situations, architects use natural elements to develop architectural parties, shapes and structures. Fractal geometry can be a pattern that enhances the development of these natural phenomena. Fractals allow geometry to assimilate and reproduce natural patterns, having its first studies carried out by Benoir Mandelbrot through mathematical patterns. These fractal models described by Mandelbrot can consistently represent natural aspects and shapes, such as mountains, clouds, trees, geographical lines, wave motion, lightning and other forms (RIAM AND ASAYAMA, 2016; MANDELBROT, 1977). 


\section{Fractal geometry}

Mandelbrot (1977) states that a fractal is a structure that has invariance, regardless of the scale in which it is observed, maintaining its original identical structure. The fractal and its patterns are derived from four main characteristics: self-similarity; infinite complexity; irregularity or roughness; and a non-whole dimension.

Self-similarity is identified when part of the figure or outline is replicated on smaller or larger scales. This feature can be observed in different proportions in the composition of the buildings and can be used in an unintended and intentional way. When unintentional, self-similarity appears mainly in the building's aesthetic relevance, details and ornaments. In intentional compositions, the characteristic of repetition is made rationally, distributing a character similar or equal to an initiating element in a given space (ROOM, 2006).

Infinite complexity refers to the recursive process for creating an element, that is, the iterations that constitute a given element, which can be unlimited, generating figures at minimal scales (MANDELBROT, 1977).

The third attribute, irregularity, has the meaning of roughness or non-smoothing and refers to pieces that have irregular, interrupted or fragmented ends in any observed scale (MANDELBROT 1977).

The last property of fractals is the dimension that the fractal has, identified by dimension $\mathrm{D}$, which states that existing fractal patterns can be analyzed and described by that dimension as trees and galaxies. In the chapter of the following section, this property will be explained in more detail, as it is relevant to the connection between geometry and stress reduction (MANDELBROT, 1977).

\section{Fractal geometry and stress reduction}

Among the aspects that drove the use of compositions with fractal facade elements are in the advantage of being a geometry with patterns developed by rules and its result allows a possible positive psychological reading of the space. This perception of fractals occurs from an interpretation that the human brain generates through the observation of objects with characteristics of fractal geometry. This interpretation occurs and varies through the characteristic described by Mandelbrot (1977), the "D" dimension.
The human being needs direct contact with natural forms and biological geometric structures, as this contact helps in mental and social health (Salingaros, 2003). The interest in organic geometric compositions and natural forms is motivated by positive brain responses, which assimilate natural environments with greater chances of survival, in addition to encouraging due to the rapid interpretation and understanding of associating a shape with fractal characteristics to a shelter, food or safety (TRACADA, 2016; JOYE, 2006).

Human vision presents different positive responses when observing figures with fractal compositions in natural organizations, mathematical processes and artificial objects. Spehar et al. (2003) comment that these different responses are influenced by the fractal dimension ' $\mathrm{D}$ ' and are present in all elements of fractal geometry, ranging from $1.0 \mathrm{D}$ to $2.0 \mathrm{D}$ to be considered compositions with fractal characteristics. And based on studies such as Wise and Rosenberg (1986) and Hargerhall, Purcell and Taylor (2004), authors like Salingaros (2003), Taylor (2006) and Joye (2007) relate a set of possible reasons that associate fractal geometry with positive human interpretations. These reasons include biological processes such as: brain organization; heartbeat; eye movement. And evolutionary extinguishing patterns, such as: information gathering: survival instinct and artistic expressions.

\section{Box-counting}

The fractal dimension, or D dimension, can identify and measure fractal structures and compositions through the Box-counting process. Various fractal objects and compositions do not contain visibly defined patterns and make interactions difficult to identify. For these objects, the Box-counting method described by Mandelbrot is a viable procedure. The fractal dimension or $\mathrm{D}$ can be determined by comparing the number of squares occupied in a mesh at different scales. The method consists of a mesh and the projection of the contours of a given figure that cross the mesh. It works by counting the boxes filled by these outlines in different mesh scales, as shown in figures 1 and 2. The average between the logarithmic difference and the number of existing boxes to cover figure, by the number of filled boxes that make up the contour of figure, corresponds to dimension $D$. If the $D$ is between the numbers 1.0 and 2.0 the evaluated composition has fractal characteristics (MANDELBROT, 1977; SPEHAR et al., 2003). 

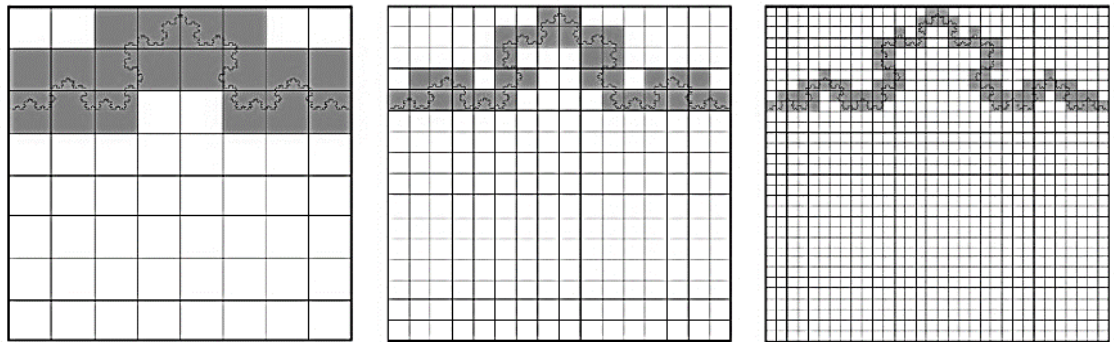

Figure 1: Example of the use of box counting in the Koch curve. Source: Rabay, (2013) adapted by the authors.

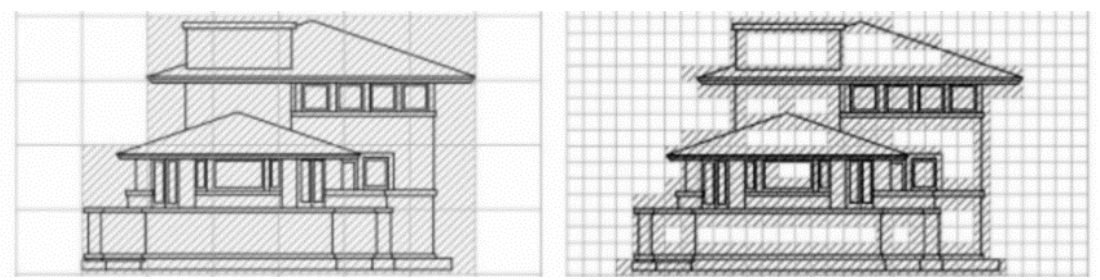

Figure 2: Robie House box counting. Source: Ostwald, Vaughan e Tucker (2014), adapted by the authors.

Counting and interpreting the $\mathrm{D}$ dimension can also contribute to the understanding of human preference for different landscapes and shapes. Studies by Pentland (1984) and Cutting and Garvin (1987) showed that there is a positive correlation in the visual interpretation of shapes modeled using fractal resources. And for Spehar et al. (2003), these different fractal dimensions are visible to the eye, and there is a human preference for figures with a $\mathrm{D}$ dimension between 1.3D and 1.5D.

\section{Fractal geometry applied in architecture}

The application of standards to guide human compositions is a common instrument in architecture and, when dealing with rules that allow natural compositions, the use of fractal characteristics is appropriate. Fractal geometry has been present in human compositions for centuries, in the field of architecture it can be found in floor plants, facades and ornaments. Currently, the use of fractal resources appears in architectural projects through computer programming and recursive processes. (SALINGAROS 2012).
According to Sedrez (2010), the characteristics of fractal geometry applied to architecture can occur in conceptual, geometric and intuitive models. Conceptual models use features and fractal patterns to guide architectural parties and design. Geometric models are those that are presented in the form of fractal characteristics of the construction, and can be analyzed by methods such as counting boxes. Intuitive models use the geometric results of fractals as inspiration.

Fractals are present in architecture in its general context or in different details and volumes. According to Joye (2007), in relation to the general context, one can analyze different architectural plans and identify fractal characteristics in their formation. As an example of this two-dimensional application, we have the fortifications of the Ba-ili villages (Zambia), the modulations of the Palmer House in Michigan (USA), among other projects. On a three-dimensional scale, the application of fractal characteristics appears more visibly, being identified in details or elements of composition as in the Hindu temples, Gothic constructions, in the Russian works of Malevich (Arkhitektoiniki), Storey Hall (Melbourne), and others. The use of fractal compositions goes beyond the field of architecture and can be used and identified in various graphic and artistic samples (JOYE, 2007).

Fractal characteristics such as self-similarity is present in works of oriental architecture, this attribute can be identified in two situations, in the composition of floor plants and shapes. In the first, this fractal pattern is observed in the repetition of different scales, as demonstrated in the Chinese temple of the Kaiyuan Si pagoda (Figure 3), where the octagonal shape is repeated in different scales (ROOM, 2003).

The application of fractal characteristics is found in the composition of shapes and configurations of African cities and towns before the insertion and colonization of European patterns. An example of the application of the self-similarity rule in the organization of these old communities is the village of Ba-ili, located in southern Zambia. This village has the shape of a half moon, repeated in various scales and patterns, reflecting the religious, natural and social influences and characteristics in its structure. (EGLASH, 1999)

The characteristic of self-similarity in the composition of floor plants and solids is also notable in different buildings in Renaissance Europe, identified mainly in ornaments and decorations. Sala (2003) describes that some of these constructions have obvious similarities to fractal patterns. During the Renaissance, the geometry used to 
develop ornaments and architecture was based on mathematics led by nature, as these proportions and rules were directly linked to a divine language.

There are indications of several architects and works that used fractal characteristics already in the 20th century. Like Antonio Gaudí (1852-1926), who developed several designs, shapes and ornaments with fractal characteristics inspirited in the natural forms. In Soviet architecture, the architect and artist Kazimir Malevich (1987-1935) developed designs and sculptures that use proportion, referring to self-similarity, as an architectural party, varying the same volume in different scales. The use of fractal characteristics, such as self-resemblance, in plans and volumes of Frank Lloyd Wright's works (1987-1959) can be identified, as in the projects of Palmer House, Robie House and Marin County Civic Center. In projects by the Italian architect Paolo Portoghesi, there is the presence of fractal characteristics to develop the plans for some works such as Villa Papadancine (1966) and Câmara de Depuits (1967). In these works, the architect used different circles scales to unify the lines that make up his plans (ROOM, 2003).

However, fractal features were first mentioned and used rationally by architect Peter Eisenman in 1978, with the 11th house, for the "Housing in Venice" contest. In this project, the architect used three concepts that can be associated with fractals, discontinuity, recursion and self-similarity. In another project by Eisenman, "Moving Arrows, Eros and Other Eros" (1985), figure 3, the architect again used fractal characteristics, dialoguing with fictional aspects. (OSTWALD, 2001).

Despite criticism received during the 1990s, offices and architects continued to use fractal features in various projects. Like architecture firm Ushida Findlay, which produced a series of designs using fractal geometry and the Fibonacci sequence (figure 3). And more recently, we can mention projects like LAB Architectures, which developed the Federation Square complex in Melbourne, Australia (LAB ARCHITECTURE STUDIO, 2017; OSTWALD, 2001).
Parametric process of a box-counting model for evaluation of fractal compositions

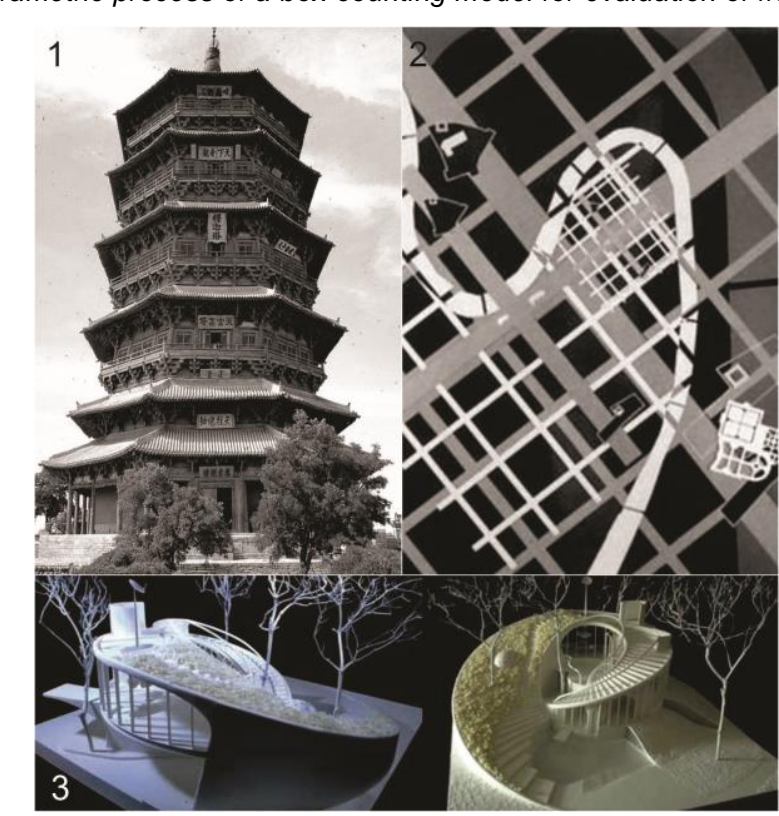

Figura 3: Comparison of three architectures that use fractals in their formal structure, first the Kaiyuan Si Pagoda's Chinese temple; The second part Moving Arrows, Eros and Other Eros, Peter Eisenman (1985); and in the thirth part the House for the Third Millenium ,Ushida Findlay Partnership, Londres, Grande-Bretagne, 1994. Source: https://br.pinter-

est.com/pin/232287293250775577/, accessed: 19/01/2021; http://mainprjkt.com/mainprojekt/series-11-weeks-eisenman-1986, access: 13/01/2021, adapted by the author. http://www.archilab.org/public/2000/catalog/ushida/find18.htm, accessed: 13/01/2021.

Sedrez and Pereira (2009) describe a list of other architects who used fractal features in their projects Charles Correa, Carlos Ferrater, Arata Isozaki, Christoph Langhof, Daniel Liebermann, Fumihiko Maki, Eric Owen Moss, Jean Nouvel, Philippe Samyn, Kazuo Shinohara, Aldo and Hannie van Eyck, Ben van Berkel and Caroline Bos, Peter Kulka and Ulrich Königs and Eisaku Ushida and Kathryn Findlay.

\section{Digital tools and indicators}

For the elaboration of this research, digital tools were applied capable of developing a parametric process. The use of these tools, aimed at architectural practice, can be enhanced with the use of visual programming tools. These programs can be created from editors integrated with virtual modeling tools, allowing professionals without deep programming knowledge to simplify codes development (ISSA, 2013). 
The increasing use of parametric tools induces architects to quantify and associate components in their projects. This process, which initially varied only in form, can be combined with codes that alter the language and efficiency of the construction. To model parametric processes within the field of architecture and design, one of the algorithm-friendly interface programs is the Grasshopper plug-in, a graphic editor connected to the Rhinoceros 3D modeler. It provides a variety of mathematical and geometric operations and commands (SALIM and BURRY, 2010; ERCAN and ELIAS-OZKAN, 2015).

To build the model desired in this article, the computational tools mentioned in this subsection were used, with the Grasshopper component being a plug-in of the Rhinoceros 3D - 5 program (licensed in educational version). The set of these digital tools constitute the main platforms for the development of the parametric process for the Box-counting model.

\section{Development of the Parametric Process}

To build the model desired in this article, the computational tools mentioned in this subsection were used, with the Grasshopper component being a plug-in of the Rhinoceros 3D - 5 program (licensed in educational version). The set of these digital tools constitute the main platforms for the development of the parametric process for the Box-counting model.

This article aims to develop a parametric process of a Box-counting method capable of identifying and dimensioning if the compositions made with façade elements with fractal characteristics present fractal patterns, dimension D between 1.0 and 2.0. Thus, before the development of the parametric process, other research was developed to create different facade elements based on the linear fractal rules that composed the arrangements tested in this section, Mariano (2018).

For this process of evaluation and verification of the $\mathrm{D}$ dimension, an arrangement is initially composed parametrically using one of the patterns of facade elements used in the work of Mariano (2018). Being the patterns: the Sierpinski rug; the set of Cantor; Minkowski curve; and the dragon's curve. Afterwards, the curves that make up the individual design of the composition panels are selected. The projections of these curves are superimposed on a mesh, created by the process, through the overlap between the curves and the mesh, all spaces in which the projected curves
Parametric process of a box-counting model for evaluation of fractal compositions

fill the mesh are counted. Then the logarithm of these two numbers (the number of unfilled mesh spaces and the number of filled spaces) is counted, the result of the unfilled mesh logarithm is divided by the logarithm of the number of spaces filled by the curve. The result of this first division is the fractal dimension of the first box count.

The process described above is carried out three times, in three different division meshes. In a grid of four by four (4x4), followed by a division of eight by eight (8x8), and the mesh with the smaller divisions consists of a grid of twelve by twelve $(12 \times 12)$

The objective of this stage of the process is to identify a fractal dimension of the composition closest to the values between 1.3 and 1.5, as these values provide positive responses to human perception and verify that the arrangements created are within 1.0 and 2,0 D that characterize them as fractals. (SPEHAR et al., 2003).

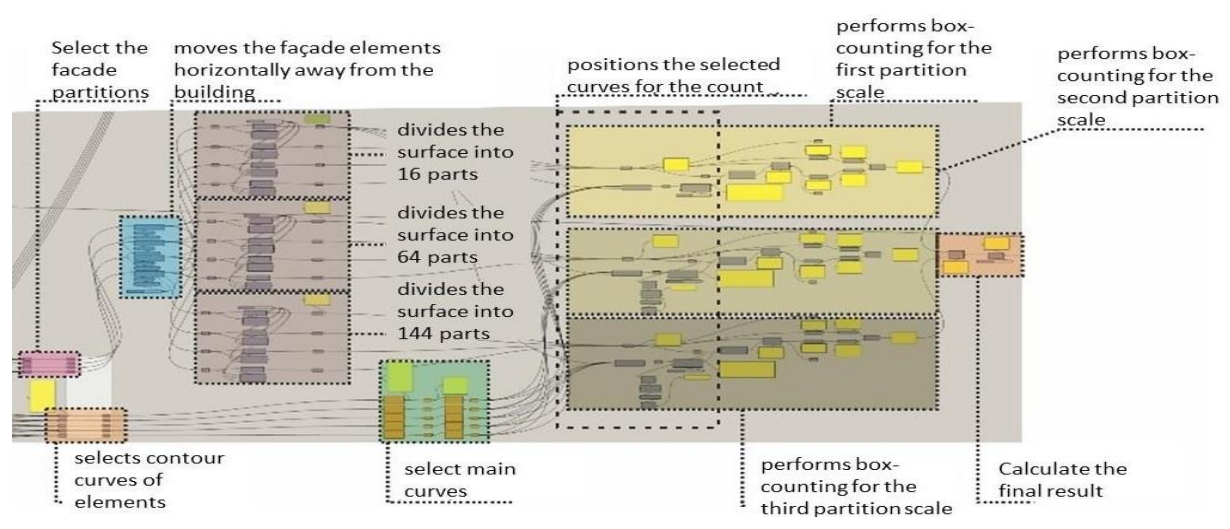

Figure 4: Visual programming for the box-counting process within the grasshopper platform Source: The Authors

The parametric process that allows the counting of the fractal dimension developed on the Grasshopper platform can be identified by figure 4. A sample of the operation and the Box-counting can be shown in figures 5 , which present a similar sequence already illustrated by figures 1 and 2 . 

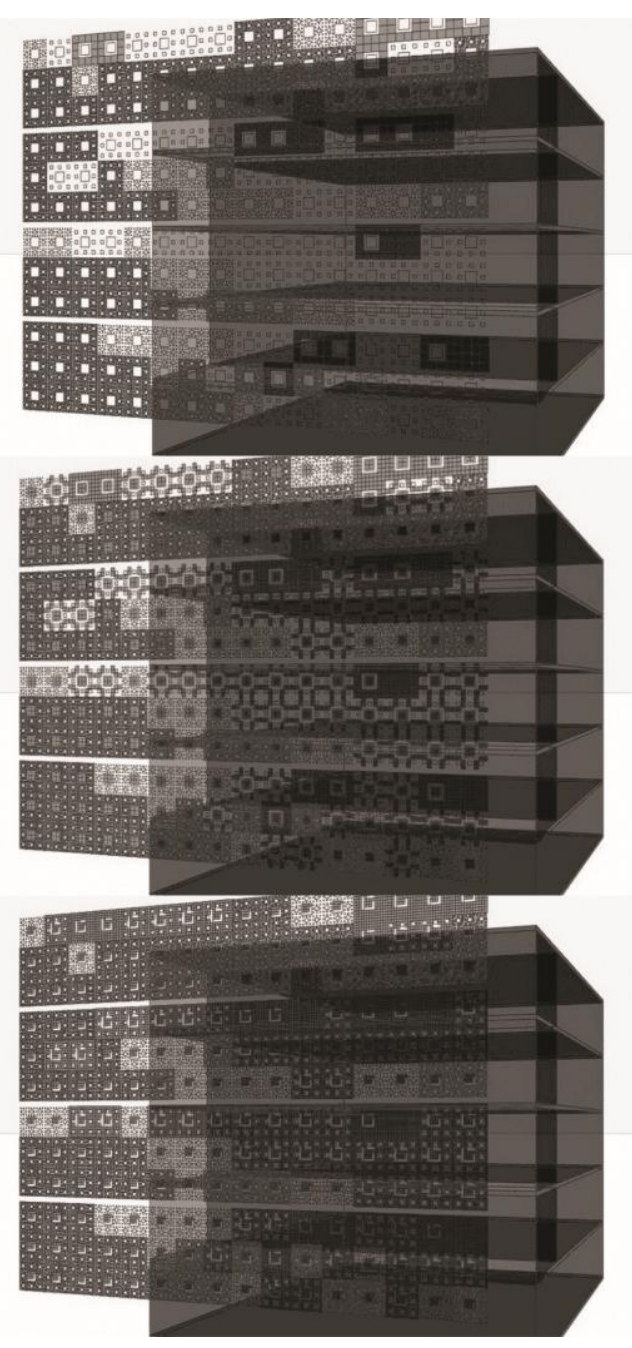

Figure 5: Projection of the curves that make up the panels for the box counting evaluation in: The Box-counting first count, (4x4); Second Box-counting, (8x8); Third Box-counting, (12x12). Source: The Authors

To validate the process, a sequence of actions was developed involving the measurement of the $\mathrm{D}$ dimension of different types of panels and compositions. For this, initially, a generic urban environment of short stature was adjusted to simulate the radiation incident in the construction of the model. Next, the five elements of the facade with characteristics of one of the fractal patterns are organized. These panels are arranged on the facade of the building according to the incident solar radiation. These panels are more iterated (more subtracted) in areas with less radiation and less iterated (less subtracted) in areas with more incident radiation. The adjustment of this mosaic can be controlled parametrically until reaching an adequate compositional result. With this organization, Box-counting is made for the facade elements of Mariano (2018). All elements are evaluated following the same organization, so that the results of the method can be compared.

With the result obtained, one of the elements is selected, which has the most favorable qualitative or quantitative characteristics. In sequence, the urban surroundings are modified, increasing the verticality of the buildings and the topography of the urban environment. Thus, the arrangement of the composition of this fractal pattern is adjusted to the new incident solar radiation (more shaded). This new incidence of radiation implies a new organization; therefore, it is intended to obtain another result of the fractal dimension and to verify if it changes with a new arrangement composition. Figure 6 shows the two environments used in the process validation.

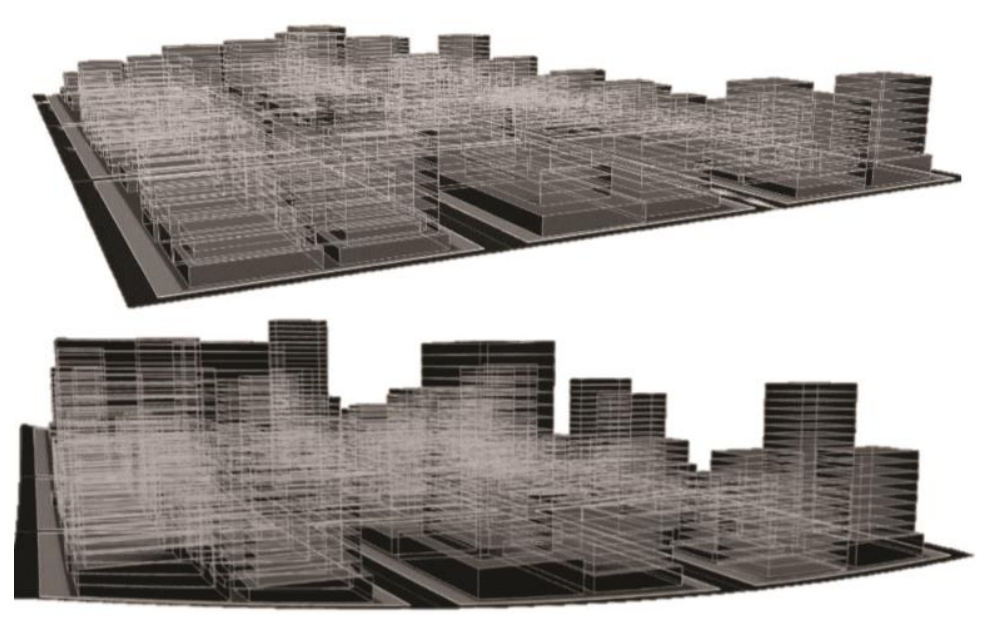

Figure 6: The two urban environments used in the process test sequence, the first with a low urban environment and the sequence with more pronounced verticality and topography. Source: The Authors 


\section{Results}

During the process verification step, the four different types of panel patterns were arranged with the same composition arrangement. Making it possible to check the fractal dimensions of the four. The fractal patterns used were: the Sierpinski carpet; the Cantor ensemble; Minkowski curve; and the dragon curve. The results of these organizations can be seen in figure 7 , which illustrates the panels used for each group of fractal pattern. The fractal dimension of each of these patterns identified by the Box-counting method can be understood in table 1 .
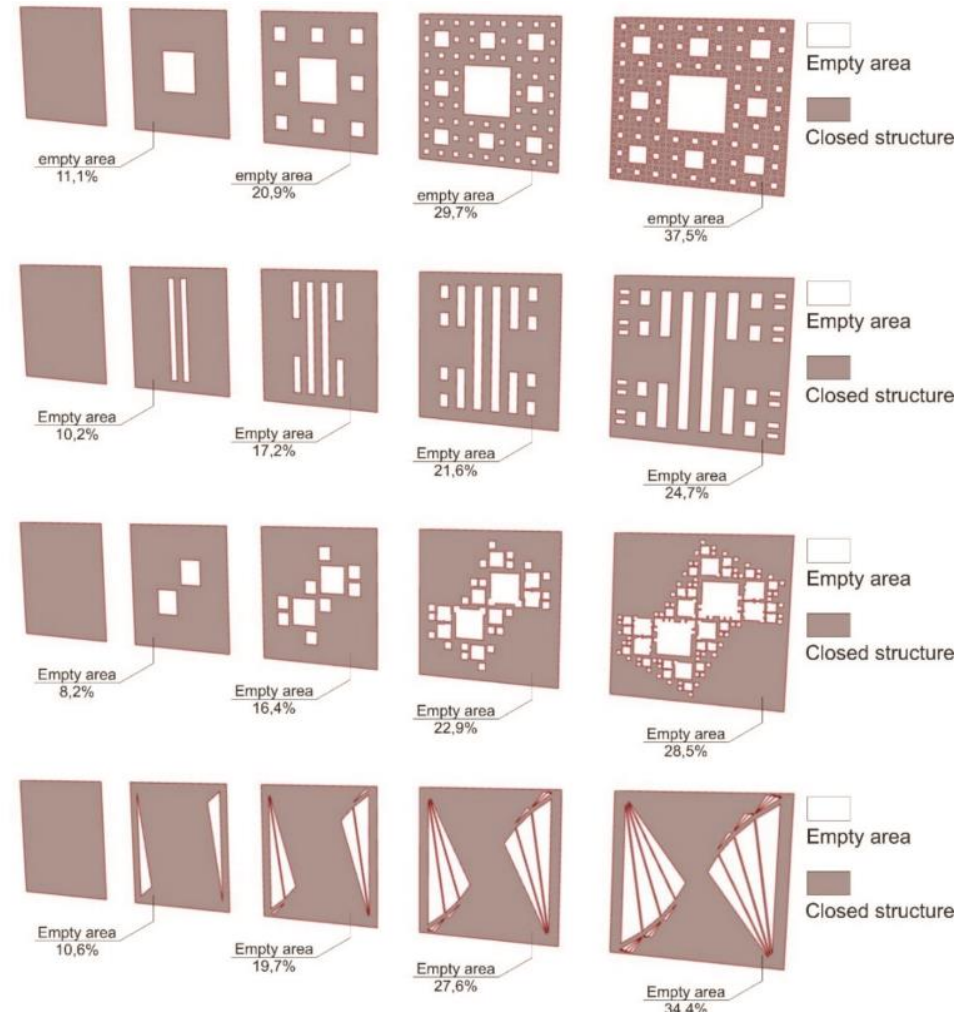

Empty area

$\frac{\text { Emply area }}{34.4 \%}$

Figure 7: Following the vertical order, we have 4 iterations of 4 fractals being: Sierpinski Carpet fractal pattern; Cantor set; Minkoski Curve; and Dragon Curve. Source: The Authors

\begin{tabular}{l|llll}
$\begin{array}{l}\text { FRACTAL } \\
\text { TYPE }\end{array}$ & $\begin{array}{l}\text { MINKOWSKI } \\
\text { CURVE }\end{array}$ & $\begin{array}{l}\text { CANTOR } \\
\text { SET }\end{array}$ & $\begin{array}{l}\text { DRAGON } \\
\text { CURVE }\end{array}$ & $\begin{array}{l}\text { SIERPINSKI } \\
\text { RUG }\end{array}$ \\
\hline $\begin{array}{l}\text { D. FRAC- } \\
\text { TAL }\end{array}$ & $1.08 \mathrm{D}$ & $1.12 \mathrm{D}$ & $1.14 \mathrm{D}$ & $1.25 \mathrm{D}$ \\
\hline
\end{tabular}

Table 1: Fractal dimension result for the parametric Box-counting. Source: The Authors

With the sequential results of Box-counting, it can be identified that the four patterns used in the sample reached a value between 1.0 and 2.0, confirming that their compositions are in fact fractal patterns. After collecting the data, one of the patterns was chosen to change the composition and check if the $D$ dimension is changed, in case the composition is modified. The pattern with the best results (closest to 1.3 to 1.5 ) was the composition made with the panels using the Sierpinski carpet. However, the type of fractal chosen for a new test was the Cantor Set, because as it is a pattern with less curves it allowed a faster response of the computer hardware used, allowing quick changes through the parametric process. The Cantor group was also chosen because it is a result a little more distant from the desired numerical range (1.3 to 1.5), which determines that the composition has to undergo more significant changes to try to reach these values.

With the new composition, using Cantor Set, it was decided to use more empty elements (third or fourth iteration). As the surrounding area had more shading elements, it was intended that the interior environment would receive more daylight and the facade would be composed of more iterated elements.

With the new arrangement, the Box-counting was tested again, and the result of the fractal dimension tended to increase to 1.21D. The comparison of the two results can be seen in table 2, a sample of the aesthetic result of the internal environment in both situations can be evaluated by figure 8 .

1을 Composition

2o Composition

D. Fractal

1.12D

1.21D

Table 2: Fractal dimension result for the second test of the Box-counting. Source: The Authors 


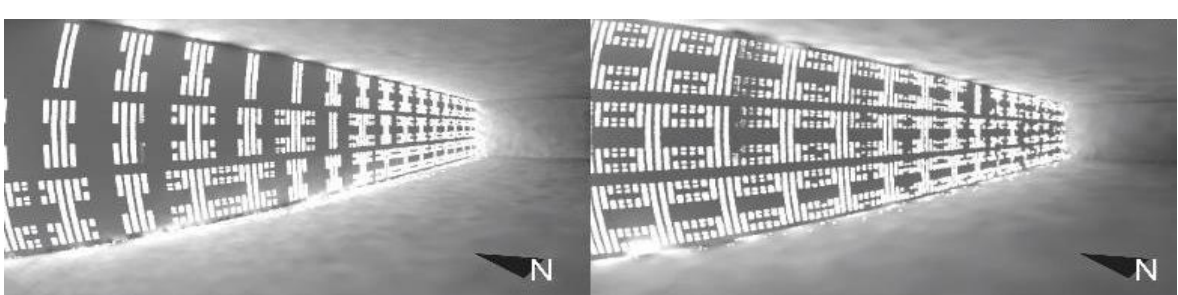

Figure 7: Internal comparison 1st floor, Cantor Set, at 15:00 on October 21st, with an urban environment of low buildings and adjacent with tall buildings. Source: The Authors.

\section{Conclusion}

With the test and collected results, it can be concluded that the parametric process with the Box-couting method allowed to identify fractal patterns in different compositions that used facade elements with fractal geometry characteristics, in an agile and dynamic way, without the need for human interaction for calculations and counts. The process was also able to identify different $D$ dimensions for the same type of pattern, but with a different organization. The parametric interface proved to be positive, coupled with the Box-counting method, as it allowed a quick analysis as the organization adjusted to receive more iterated elements. The test with a set of Cantor to try to reach a fractal dimension between 1.3 and 1.5, demonstrated in a simultaneous and visual way, a relationship between the number of elements more iterated with dimension $\mathrm{D}$. Presenting a relationship already known but that can be visualized using the process.

Observing the fractal dimension of the two compositions with the Cantor ensemble, it can be noted that the larger the area used, which fills the surface comprising the facade elements with fractal characteristics, the greater the $D$ dimension achieved. However, even with the increase in the use of more iterated panels in the second organization, the range $1.3 \mathrm{D}$ to $1.5 \mathrm{D}$ has not yet been reached. Demonstrating that a greater number of iterations is necessary for the composition result to be more fragmented. This visualization during Box-counting tests made it possible to state that the number of iterations that a fractal has is directly related to its $D$ dimension, the more iterations have the elements used in the composition, the higher the result of the $\mathrm{D}$ dimension of the arrangement.
With the analysis of the results of the composition of the Cantor Set, it was possible to identify that even using a larger number of more iterated panels, the results of the Box-counting demonstrated that it was not enough to reach a dimension greater than 1.3D. However, as the results of the Sierpinski carpet in the initial configuration have already reached values close to 1.3D, it is understood that, if the same configuration used in the Cantor Set sequence was used in this pattern, it would reach the ideal range. However, even with a quick response from the parametric process, some hardware difficulties were identified, which led to the advance of research to other areas, such as natural lighting and others. Thus, the experimentation of other tests that would complement the article was designed for future research.

\section{Referências}

CUTTING, James E.; GARVIN, Jeffrey J.. Fractal curves and complexity. Perception \& Psychophysics, v. 42, n. 4, p.365-370, July. 1987. Springer Nature. http://dx.doi.org/10.3758/bf03203093.

EGLASH, Ron. African Fractals: Modern Computing and Indigenous Design. Rutgers University, 1999. $265 \mathrm{p}$.

ERCAN, Burak; ELIAS-OZKAN, Soofia Tahira. Performance-based parametric design explorations: A method for generating appropriate building components. Design Studies, v. 38, p.33-53, May 2015. Elsevier BV. http://dx.doi.org/10.1016/i.destud.2015.01.001.

HARRIS, James. Integrated Function Systems and Organic Architecture from Wright to Mondrian. Nexus Network Journal, p.93-101, 2007. Birkhäuser Basel. http://dx.doi.org/10.1007/978-3-7643-8519-4 6.

HAGERHALL, Caroline M; PURCELL, Terry; TAYLOR, Richard. Fractal dimension of landscape silhouette outlines as a predictor of landscape preference. Journal of Environmental Psychology, v. 24, n. 2, p.247-255, June 2004. Elsevier BV. http://dx.doi.org/10.1016/i.jenvp.2003.12.004.

ISSA, Rajaa. Essential Mathematics: for computational design. 3. ed.: Robert Mcneel \& Associates, 2013. 79p. 
JOYE, Yannick. Fractal Architecture Could Be Good for You. Nexus Network Journal, v. 9, n. 2, p.311-320, October 2007. Springer Nature. http://dx.doi.org/10.1007/s00004-007-0045-y.

LAB Architecture Studio. 2017. Disponível em: <http://www.labarchitecture.com> . 2018.

LANGHEIN, Joachim. Proportion and Traditional Architecture. Proportion and Traditional Architecture, v. 1, n. 10, p.1-21, 2005.

MANDELBROT, Benoit B.. The Fractal Geometry of Nature. Nova lorque: W. H . Freeman and Company, 1977. 480p.

MARIANO, Pedro Oscar Pizzetti. Processo De Projeto Paramétrico De Elementos De Fachada Com Características Da Geometria Fractal Con. 2018. $189 \mathrm{f}$. Dissertação (Mestrado) - Curso de Arquitetura e Urbanismo, Projeto e Tecnologia do Ambiente Construído, Universidade Federal de Santa Catarina, Florianópolis, 2018.

MARIANO, Pedro Oscar Pizzetti; PEREIRA, Alice Theresinha Cybis; VAZ, Carlos Verzola. Avaliação luminosa de elementos de fachada com características fractais. Parc Pesquisa em Arquitetura e Construção, [s.l.], v. 9, n. 1, p.3-18, 31 mar. 2018. Universidade Estadual de Campinas. http://dx.doi.org/10.20396/parc.v9i1.8650255.OSTWALD, Michael J.. "Fractal Architecture": Late Twentieth Century Connections Between Architecture and Fractal Geometry. Nexus Network Journal, v. 3, n. 1, p.73-84, April 2001. Springer Nature. http://dx.doi.org/10.1007/s00004-000-0006-1.

PENTLAND, Alex P.. Fractal-Based Description of Natural Scenes. IEEE Transactions on Pattern Analysis And Machine Intelligence, v. -6, n. 6, p.661-674, November 1984. Institute of Electrical and Electronics Engineers (IEEE). http://dx.doi.org/10.1109/tpami.1984.4767591

RIAN, lasef Md; ASAYAMA, Shuichi. Computational Design of a nature-inspired architectural structure using the concepts of self-similar and random fractals. Automation in Construction, v. 66, p.43-58, June 2016. Elsevier BV. http://dx.doi.org/10.1016/i.autcon.2016.03.010.
RUMIEZ, Agnieszka. Fractal Architecture. Architecture and Urban Planning, v. 8, p.45-49, 19 Dezember 2013. Riga Technical University. http://dx.doi.org/10.7250/aup.2013.019.

SALA, Nicoletta. Fractal Geometry and Self-Similarity In Architecture: An Overview Across The Centuries. The International Society of The Arts, Mathematics, And Ardlitecture, p.235-244, 2003.

SALA, N.. Fractal geometry and architecture: some interesting connections. Eco-architecture: Harmonisation between Architecture and Nature, p.163-173, 7 June 2006. WIT Press. http://dx.doi.org/10.2495/arc060171.

SALIM, Flora Dilys; BURRY, Jane. Software Openness: Evaluating Parameters of Parametric Modeling Tools to Support Creativity and Multidisciplinary Design Integration. Computational Science and its Applications - Iccsa 2010, p.483-497, 2010. Springer Berlin Heidelberg. http://dx.doi.org/10.1007/978-3-642-12179-1 40.

SALINGAROS, N. A. (2003). The sensory value of ornament. Communication \& Cognition, 36 (3-4), 331-351.

SALINGAROS, Nikos A.; MEHAFFY, Michel W. A Theory of Architecture. Intercollegiate Studies Institute, 2007. $278 \mathrm{p}$.

SEDREZ, Maycon Ricardo; PEREIRA, Alice T. Cybis. CAAD e Criatividade, uma experiência com arquitetura fractal. Risco, Eesc-usp, v. 9, n. 1, p.168-179, 2009.

SEDREZ, Maycon Ricardo. A CONTRIBUIÇÃO DA ARQUITETURA FRACTAL PARA O ENSINO DE CAAD. Oculum Ensaios, Campinas, v. 12, n. 11, p.55-57, jan. 2010.

SPEHAR, Branka et al. Universal aesthetic of fractals. Computers \& Graphics, v. 27 , n. 5, p.813-820, out. 2003. Elsevier BV. http://dx.doi.org/10.1016/s00978493(03)00154-7.

TAYLOR, R.p.. Reduction of Physiological Stress Using Fractal Art and Architecture. Leonardo, v. 39, n. 3, p.245-251, jun. 2006. MIT Press - Journals. http://dx.doi.org/10.1162/leon.2006.39.3.245. 
TRACADA, Eleni. BIOPHILIC URBAN DEVELOPMENTS FOLLOWING DYNAMIC FLOWS OF TREE-SHAPED ARCHITECTURES. International Journal of Heat And Technology, v. 34, n. 1, p.161-166, 31 jan. 2016. International Information and Engineering Technology Association. http://dx.doi.org/10.18280/ijht.34s121.

WAIHRICH, Lorena P. et al. PESQUISA DE PADRÕES E SUAS APLICAÇÕES EM ARQUITETURA E URBANISMO: ênfase em Geometria Fractal. Mecânica Computacional, Buenos Aires, Argentina, v., n. [1], p.6341-6359, nov. 2010.

WISE, James A. ROSENBERG, Erika. The Effects of Interior Treatments on Performance Stress in Three Types of Mental Tasks. Technical Report, Space Human Factors Office. NASA-ARC, 1986. 